\title{
Reviewing the relations between teachers' knowledge and pupils' attitude in the field of primary technology education
}

\author{
Ellen J. Rohaan · Ruurd Taconis • Wim M. G. Jochems
}

Published online: 5 June 2008

(C) The Author(s) 2008

\begin{abstract}
This literature review reports on the assumed relations between primary school teachers' knowledge of technology and pupils' attitude towards technology. In order to find relevant aspects of technology-specific teacher knowledge, scientific literature in the field of primary technology education was searched. It is found that teacher knowledge is essential for stimulating a positive attitude towards technology in pupils. Particularly, teachers' enhanced Pedagogical Content Knowledge is found to be related to pupils' increased learning and interest in technology. Six aspects of technology-specific teacher knowledge that are likely to play a role in affecting pupils' attitude are identified and schematically presented in a hypothetical diagram. It is concluded that more empirical evidence on the influence of technology-specific teacher knowledge on pupils' attitude is needed. The hypothetical diagram will serve as a helpful tool to investigate the assumed relations between teacher knowledge and pupils' attitude empirically.
\end{abstract}

Keywords Attitude towards technology - Pedagogical Content Knowledge · Primary education - Subject Matter Knowledge - Teacher knowledge ·

Technology education

\section{Introduction}

When people lived as hunters and gatherers, they needed to know about and understand their natural environment in order to survive. In modern times, we need to know about and understand our technological environment. The technological world is developing fast and technology takes a constantly growing place in today's society. Consequently, education needs to adapt to this increasing importance of technology, and educational programmes should be aimed at developing pupils' technological literacy. As the International Technology Education Association (ITEA) propagates, all pupils should learn to think critically

E. J. Rohaan $(\bowtie) \cdot$ R. Taconis · W. M. G. Jochems

Eindhoven School of Education, Eindhoven University of Technology, P. O. Box 513, 5600 MB

Eindhoven, The Netherlands

e-mail: ellen.rohaan@esoe.nl 
about how to design, develop, and implement products, systems, and environments to solve practical problems (ITEA 2006). Technology education should develop an understanding of the nature of technology, the relationship between technology and society, and technological design. Through technology education, pupils will understand the most important areas of the 'designed world', i.e., medical, agricultural, energy and power, information and communication, transportation, manufacturing, and construction technologies. In short, technology education ought to make pupils technological literate in a broad sense (ITEA 2007).

A document of the Organization for Economic Co-operation and Development (OECD) about the evolution of pupils' interest in science and technology studies, reports that in the last 15 years the numbers of science and technology students have been decreasing in relative terms. This trend is worrying with respect to the continuing transition to a more technology-intensive economy. In contrast, pupils in primary schools generally show a natural curiosity for science and technology. It is argued that most primary teachers apparently lack the ability and confidence to develop and stimulate this natural curiosity for technology (OECD 2006).

Regarding a growing need for engineers and technologists, it is important to know if stimulating 10-12 years old pupils' attitude towards technology affect their study and career choices later on in life. As far back as in 1927, a prominent study showed that vocational interest is an enduring characteristic of an individual that is easily observed and can be used to predict a person's choices and behavior (Boekaerts and Boscolo 2002). This finding implies that attitude, which usually comprises vocational interest, is a good predictor for study and career choices later in life. It seems likely that the earlier attitude towards technology is positively stimulated, the more persistent and predictive it will be. Although, strong empirical evidence is still lacking.

In studies on pupils' attitude towards technology, it is found that pupils' positive attitude is often related with a correct and comprehensive concept of technology. With emphasis on only few specific aspects of technology, there is considerable risk that pupils develop a limited concept of technology. Hence, it is important that teachers have a correct and comprehensive concept of technology in order to be able to shape their pupils' attitude (De Vries 2000).

In their book 'How people learn', Bransford et al. (2004) concluded

"Outstanding teaching requires teachers to have a deep understanding of the subject matter and its structure, as well as an equally thorough understanding of the kinds of teaching activities that help students understand the subject matter in order to be capable of asking probing questions" (p.188).

This quote implies that not only a correct and comprehensive concept of technology, but subject-specific teacher knowledge in general is important for successful technology education. Primary school teachers, who are educated to teach a wide variety of subjects, will therefore need a thorough understanding of the subject matter of technology to know which topics to address and how to address them in their technology lessons. Until now, little scientific research on the role of teacher knowledge in the field of primary technology education has been done.

In this literature review the relations between primary school teachers' knowledge of technology and technology education, on the one hand, and pupils' attitude towards technology, on the other, are theoretically explored. The central aim is to elucidate how technology-specific teacher knowledge affects pupils' attitude towards technology. Insights 
into this relationship will help teacher educators to train primary school teachers in the field of technology education.

First, a hypothetical diagram of six aspects of technology-specific teacher knowledge, their interrelationships, and their relations with pupils' attitude, is presented. Next, these six aspects of teacher knowledge and their relations are described in more detail. Then, the relation between pupils' concept and attitude is clarified. In the concluding section, the findings are summarized and critically discussed.

\section{Technology-specific teacher knowledge}

Teacher knowledge is an umbrella term that covers a large variety of cognitions, beliefs, skills, and knowledge domains. Various labels have been used by researchers underlining the different appearances of teacher knowledge (e.g., 'wisdom of practice', 'professional craft knowledge', 'action oriented knowledge'). According to Verloop et al. (2001), teacher knowledge comprises the whole of knowledge and insights that underlies teachers' actions in practice, including tacit knowledge.

It is said that a teacher should be able to combine subject matter knowledge and pedagogical knowledge for effective coaching of pupils' learning processes. This implies that a teacher should know about particular subject-related difficulties and should know how to handle these difficulties, for example, by explaining the same subject matter in different ways (Verloop et al. 2001). This specific domain of teacher knowledge is called 'Pedagogical Content Knowledge' (PCK) and was first examined by the American educationalist Lee Shulman. He defined it as "a special amalgam of content and pedagogy that is uniquely the province of teachers, their own special form of professional understanding" (Shulman 1987, p. 8).

In order to find relevant aspects of teacher knowledge regarding technology education, recent scientific literature in the field of primary technology education was searched thoroughly. Articles that mentioned specific aspects of teacher knowledge or pupils' attitude towards technology were included in the review. When literature on primary technology education on certain topics was not available, literature on secondary technology education was included instead. When necessary, literature on primary science education was used as well.

Based on the reviewed literature, six technology-specific knowledge aspects, which can be categorized into three domains, (A) Subject Matter Knowledge (SMK), (B) Pedagogical Content Knowledge (PCK), and (C) Attitude, are defined. In the domain of SMK the aspects (1) general SMK (Parkinson 2001; Davis et al. 2002), and (2) concept of technology (Jarvis and Rennie 1996a; Cunningham et al. 2006; De Vries 2000) are classified. The domain of PCK consists of the aspects (3) knowledge of pupils' concept of technology, and knowledge of pupils' pre and misconceptions related to technology (Davis et al. 2002; Jarvis and Rennie 1996b), (4) knowledge of pedagogical approaches and teaching strategies for technology education (Boser et al. 1998), and (5) knowledge about the nature and purpose of technology education (Jones and Moreland 2004). The third domain and sixth aspect is (6) attitude towards technology and confidence in teaching technology (Johnston and Ahtee 2006). These six aspects of technology-specific teacher knowledge are schematically presented in a hypothetical diagram (Fig. 1). This diagram structurally outlines hypothetical relations $(\mathrm{a}-\mathrm{h})$ between aspects concerning teacher knowledge and pupils' attitude. 


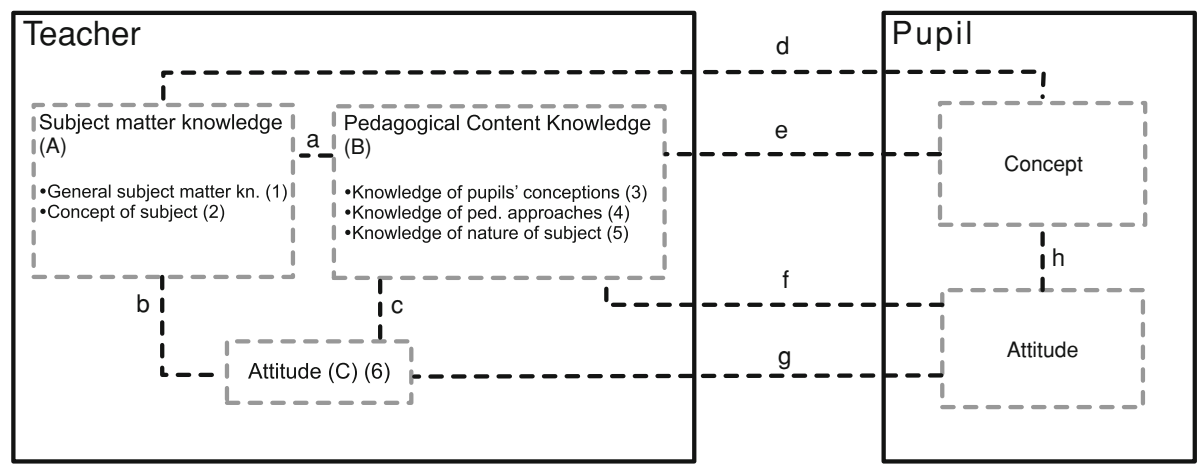

Fig. 1 Hypothetical diagram of relations between teachers' knowledge and pupils' attitude

In the following subsections, the teacher knowledge domains (A, B and C), their assumed interrelationships (a, b, and c) and their hypothetical relations with pupils' concept of and attitude towards technology (e, f, g, and h) are discussed.

\section{Subject Matter Knowledge}

In this subsection the domain of SMK (A) and the hypothetical relation between SMK and pupils' concept (d) are discussed (see Fig. 1). The categorization of SMK in two aspects, general SMK of technology and concept of technology, is based on Grossman's model of teacher knowledge. In this model, SMK includes understanding the content of a subject area, as well as knowledge of the substantive and syntactic structures of the discipline. Grossman states that without knowledge of the structures of a discipline, teachers may misrepresent both the content and the nature of the discipline itself (Grossman 1990).

With respect to understanding the subject matter, Parkinson (2001) recommended that pre-service primary school teachers should clarify and reconstruct their own misconceptions related to technology. He argued that the more active pre-service teachers are in constructing their own knowledge, the more able they will be to enhance their pupils' learning. Additionally, the more teacher's SMK is shaped in a scientifically and technologically correct way, the less likely it is that teachers will encourage pupils' development of inappropriate conceptions (Parkinson 2001). In line with this statement, Davis (2002) advocates that all pre-service and in-service primary school teachers should be better informed about the key areas of technology.

In order to define the key areas of technology, the ITEA (2006) listed ten fundamental concepts ('universals of technology'). The universals are categorized into three groups, (A) Knowledge, (B) Processes, and (C) Contexts. Group A is comprised of the concepts (1) nature and evolution of technology, (2) linkages, and (3) technological concepts and principles. Group B contains (4) designing and developing, (5) determining and controlling, (6) utilizing, and (7) assessing impacts and consequences. To group $\mathrm{C}$ belong (8) biological and chemical systems, (9) informational systems, and (10) physical systems (ITEA 2006). From these universals more detailed content elements for the study of technology were developed and thoroughly described in the Standards for Technological Literacy (STL) document (ITEA 2007).

Besides understanding the subject matter, which could be tagged as 'conceptual knowledge', two other knowledge aspects are reported to be important in technology 
education, i.e., metacognitive strategies and procedural knowledge. Metacognitive strategies, which include scaffolded inquiry, reflection, and generalization, is supposed to be important in the development of technological literacy and specifically important in problem solving activities. Procedural knowledge is related to the design component of technology education, and is necessary to successfully solve a design problem (Garmire and Pearson 2006).

The second aspect of SMK is teachers' concept of technology, i.e., their perception of the subject. Interviews from an English study (Jarvis and Rennie 1996a) on primary school teachers' perceptions about technology indicated that teachers have a wide range of ideas about technology. These perceptions differ from very narrow views ('technology is applied science') to more sophisticated ones ('technology is designing and making artifacts that fulfil a need'). The researchers found that even teachers in the same school had different perceptions and that a lot of teachers thought of technology exclusively in the school context, usually referring to model-making. A teacher's narrow perception may inhibit pupils' understanding of technology and may lead to pupils considering technology as irrelevant to adult ('real') life. Another finding was that some of the teachers, who used science to explain technology, appeared to be confused about the general concepts of science and technology. It was concluded that teachers not only need to explore their concept of technology, but that the differences and similarities between technology and science need to be clarified too (Jarvis and Rennie 1996a).

In line with the study above, Cunningham (2006) explored primary school teacher's basic concept of technology in the USA. She found that teachers' sense of what counts as technology is often non-scientific and grows from common usage in conversation and writing. According to the researcher, this is partly caused by the vague definitions presented to the teachers by the government. Without more specific definitions it is very difficult to determine what is technology and what is not (Cunningham et al. 2006). As mentioned before, if teachers do not have a correct and comprehensive concept of technology themselves, they will not be able to transfer a correct and comprehensive concept to their pupils (De Vries 2000).

\section{Pedagogical Content Knowledge}

In this subsection the domain of PCK (B) and its hypothetical relations (a, e and f) are discussed (see Fig. 1). In the model of teacher knowledge, Grossman (1990) presented PCK as an unique and central domain that includes four central components, (1) knowledge and beliefs about the goals for teaching a subject at different grade levels, (2) knowledge of pupils' understanding and (mis)conceptions of particular topics in a subject matter, (3) curricular knowledge, i.e., knowledge about the content of the courses within one field and about the available materials, and (4) knowledge of instructional strategies and representations for teaching particular topics knowledge of context (Grossman 1990). As usual, not every researcher agrees on this conceptualization, which results in a proliferation of definitions.

In an attempt to clarify the nature and structure of PCK, Van Driel et al. (1998) compared conceptualizations by different researchers. They concluded that there is no universally accepted conceptualization, but that all researchers seem to agree on two core elements: (1) understanding of students' specific learning difficulties, and (2) knowledge of representations of the subject matter to overcome these difficulties. Furthermore, they 
underline that research on PCK is valuable, because it provides insights into the instruction process, i.e., how teachers transform SMK into meaningful student learning.

Mainly based on the work of Grossman (1990) and Van Driel et al. (1998), three aspects in the domain of PCK were identified. Firstly, an important aspect is teachers' knowledge of pupils' general concept of technology and specific conceptions related to technology. According to various studies on primary technology education, a good awareness of pupils' pre and misconceptions, which they acquire and develop through engagement in technology education, has a positive effect on technology teaching (Davis et al. 2002; Jarvis and Rennie 1996b). In addition, Lewis (1999) asserted that knowledge of the technology concepts pupils possess is important for effective teaching and improved learning.

Secondly, knowledge of different pedagogical approaches and teaching strategies that are effective in technology education seems important, although this aspect is less established in the scientific literature as an influential aspect of PCK regarding pupils' attitude. However, it seems obvious that teaching will be more effective if the teacher knows what approach or strategy is most appropriate in certain situations.

Teachers use a lot of different pedagogical approaches to teach technology. Some teachers integrate technology with other disciplines, while others focus on finding creative solutions for a technical problem. Boser et al. (1998) classified the approaches typically used in secondary (middle school) technology education in four categories: (1) the industrial arts approach, focussing on understanding of industrial technology and including activities such as using tools, machines and materials, (2) the integrated approach, incorporating other disciplines such as science and social studies, (3) the modular approach, which consists of individualized, action-based units of instruction, and (4) the problem solving approach, in which critical thinking is emphasized. The researchers measured pupils' attitude towards technology with a questionnaire to provide insights into effective teaching approaches of technology education. Although attitudes were slightly affected in a positive as well as a negative direction, no clear directions of change in attitude that resulted from any of the four pedagogical approaches were found (Boser et al. 1998).

Similarly, several other studies hypothesized the teaching method or pedagogical approach would affect pupils' learning and attitude. Stables (1997) recommended the 'hands-on' exploration in the context of problem solving, in which pupils are thinkers as well as doers, as the best way of teaching technology in primary schools. In a quantitative study about gender-based preferences for instructional approaches in secondary (middle and high school) technology education, it was found that both boys and girls were more interested in 'doing' activities (Weber and Custer 2005). In a qualitative study the 'handson' approach was again advocated for primary school pupils, but the researchers added that pupils' understanding of technology can be best achieved when the presented problems are authentic (Twyford and Järvinen 2000). In a study that compared traditional and innovative technology programmes, i.e., less handicraft-based and promoting creativity, problemsolving, and collaborative skills, in secondary schools, innovative programmes were found to have larger effects on pupils' attitudes than more traditional programmes (Volk et al. 2003).

In a review study, teaching methods were found to be one of the factors that enhance effective learning and teaching in technology education. Most researchers seemed to agree that effective teaching of technology requires a wide range of teaching methods, e.g., inquiry learning, collaborative learning, and cross-curricular learning. However, it was concluded that more scientific research evidence is required to draw solid conclusions 
about which teaching methods are most favorable (Wilson and Harris 2003). In a follow-up review, this conclusion was repeated (Wilson and Harris 2004).

Thirdly, teachers' knowledge of the nature and purpose of technology education is assumed to play an essential role in technology education. This aspect influences, among other things, what the teacher highlights as important (Jones and Moreland 2004) and, in turn, what the pupils are being taught.

On the whole, PCK is a vital domain of teacher knowledge. The New Zealand researchers Jones and Moreland (2004) found that enhanced PCK is associated with enhanced learning of pupils in primary technology education, and specifically with increased motivation and interest in technology. In related studies on the implementation of technology education in New Zealand, the important influence of PCK on technology teaching was affirmed (Jones and Compton 1998; Jones et al. 2004; Moreland and Jones 2000). The results of several other studies in primary technology education (Alamäki 1999; Fox-Turnbull 2006; Stein et al. 2002) and primary science (Davis 2004; Smith 1999) are in line with this finding.

Magnusson et al. (1999) presented two important ideas about PCK. First, within each aspect of PCK teachers possess topic-specific knowledge, for example, knowledge about misconceptions that pupils often have about electricity. Hence, effective teachers need to develop knowledge regarding all aspects within all topics they teach. Second, the aspects function as a whole. Consequently, a lack of coherence between the aspects is problematic and teacher's knowledge of one particular element may not be predictive of his or her teaching practice. For that reason, it is important to know how strong the aspects are tuned to each other and how this degree of tuning affects teaching (Magnusson et al. 1999).

Furthermore, Van Driel et al. (1998) illustrated that most researchers assumed SMK to be an essential prerequisite for the development of PCK. In other words, "strong and useful pedagogical content knowledge cannot be built on a shaky content foundation" (Smith 1999, p. 181).

Attitude towards technology

In this subsection the domain of teachers' attitude (C) and its hypothetical relations (b, c and g) are discussed (see Fig. 1). Teacher's attitude towards technology and confidence in teaching technology are other important aspects with respect to pupils' attitude towards technology. These aspects do neither fit easily into the domain of SMK, nor to the domain of PCK, because they are affective rather than cognitive aspects. However, attitude and confidence are considered to be part of the general construct of teacher knowledge (Verloop et al. 2001).

Primary school teachers have very limited or narrow perceptions of design and technology and such views may affect adversely their ability and confidence to teach the key learning area of design and technology in the classroom. In a study that aimed to broaden pre-service teachers' perceptions of technology and technology education, many pre-service teachers believed that they had achieved the confidence and capability to teach design and technology in primary school after engagement in a technology unit of study (McRobbie et al. 2000). This finding implies that enhanced knowledge is related to enhanced confidence.

Relations between attitude, confidence, SMK, and PCK were investigated in a study on pre-service teachers teaching physics in primary schools. The researchers assumed it to be important that pre-service teachers have confidence in their own SMK and PCK in order to 
support the development of understandings, skills, and attitudes in their pupils. Although the results did not clearly affirm these relations, the researchers still believed that attitudes and confidence are related in teaching physics, but that confidence not necessary results from or in good SMK and PCK. The researchers recommended that teacher education should first focus on forming positive attitudes and then on increasing SMK and PCK (Johnston and Ahtee 2006).

In a study on the role of confidence in teaching creativity in technology education, it was concluded that secondary technology teachers hamper creativity in their pupils if they themselves lack confidence about their understanding of creativity in technology education. Teachers with low confidence were frustrated about keeping their knowledge and skills updated and failed to encourage pupils which in turn lead to a negative attitude towards technology education (Davies 2000). Generalizing these findings, it is expected that a teacher who has a negative attitude towards technology or has little confidence in teaching technology, reflects this in the classroom, and in turn affects pupils' attitude towards technology.

\section{Pupils' concept and attitude}

In the hypothetical diagram (see Fig. 1), teachers' PCK and attitude are assumed to be directly related to pupils' attitude towards technology (relations $\mathrm{f}$ and $\mathrm{g}$ ). Furthermore, SMK is seen as a direct prerequisite of PCK (relation a). Besides, SMK and PCK affect pupils' attitude towards technology in an indirect way, through pupils' concept of technology (relation $\mathrm{d}$ and e). In this section, the relation between pupils' concept of technology and their attitude towards technology is further clarified (relation h).

In 1986 an international project called 'Pupils' Attitude Towards Technology (PATT)', with the purpose to develop an instrument to measure pupils' attitudes, was started. In this context 'attitude' was used as a collective term for someone's affinity, behavior and conceptualization in relation to technology. The PATT instrument is a questionnaire, which consists of 6 scales that measure the Affective and Behavioral components (ABscales: interest, role pattern, consequences, difficulty, school and career) and 4 scales that measure the Cognitive component (C-scales: society, science, skills and pillars) of attitude towards technology.

In a PATT study among 10 to 12-year-old pupils in the Netherlands, the affective and behavioral part of their attitude towards technology was measured with a PATT questionnaire (Dutch version for primary schools) and their concept of technology with use of drawing tasks and interviews. It was found that the 10 to 12 -year-old pupils had a positive attitude towards technology and that boys had a more positive attitude than girls. However, it seemed that pupils were not aware of the daily influence of technology in their lives and that their general concept of technology was rather poor (De Klerk Wolters 1989).

From a path analysis with three variables, Gender, Affect (score on AB-scales), and Concept (score on C-scales), it appeared that Concept influences Affect and not the other way around. This result indicates that a correct and comprehensive concept corresponds with a positive attitude towards technology. Pupils' concept was operationalized beforehand as consisting of four aspects: (1) society: technology is controlled by humans, (2) science: technology and science are mutually influenced, (3) skills: technology is related to designing, making and using, and (4) pillars: matter, energy and information are the pillars of technology. Besides, teachers had to fill in a questionnaire to measure their attitudes 
towards technology. Remarkably, no influence of teachers' attitude on pupils' attitude was found (De Klerk Wolters 1989).

In order to identify which perceptions pupils have of technology, Cunningham et al. (2005) assessed both primary and secondary school pupils using picture questionnaires. Most pupils appeared to have a limited and often incorrect view of what technology is. Pupils associated technology mostly with power and electricity. It was concluded that education should help pupils to develop a concept of technology that is more robust and accurate, and in turn, develop a more positive attitude (Cunningham et al. 2005).

Jarvis and Rennie (1996a) share the opinion that it is important to be informed about primary pupils' concept of the term 'technology' and how this concept develops. They reasoned that if primary school pupils associate the appropriate broad and positive technology experiences with technology, they are more likely to value and choose technology as a study or career later in life. Therefore, they conducted a study to chart pupils' development of the concept of technology. The results indicated that many pupils have a narrow concept of technology, i.e., associating technology only with computers and modern appliances. Nonetheless, the pupils showed a wide variety of ideas, with the more complex and coherent ideas among the older ones. As a concluding remark, the researchers recommended that if all teachers point out which classroom activities are related to technology, more pupils will be able to make sense of the word 'technology' in different contexts (Jarvis and Rennie 1996a).

From the PATT studies it can be concluded that pupils who have a narrow view of technology, have less positive attitudes towards technology. Unfortunately, but not fully accidentally, these pupils tend to be mostly girls. Girls usually have more interest in the social and human aspects of technology, but these aspects are rarely associated with technology. Because of their narrow concept, they are hampered in their development of a positive attitude. Therefore, it is of great importance that at primary schools technology education is taught in a way that provides a comprehensive concept, including the human and social aspects (De Vries 2000).

\section{Conclusion and discussion}

The aim of this review was to explore how technology-specific teacher knowledge relates to pupils' attitude towards technology. In a hypothetical diagram all the assumed relations between domains of teacher knowledge and pupils' concept and attitude were structurally outlined (see Fig. 1). Regarding the domain of SMK (A) and its relations (a, b, and d), both general SMK and the concept of technology are reported to be important knowledge aspects for teaching technology (Parkinson 2001; Davis et al. 2002; Garmire and Pearson 2006; Jarvis and Rennie 1996a; Cunningham et al. 2006). It is generally assumed that SMK is a prerequisite for the development of PCK (Van Driel et al. 1998). Furthermore, it is found that SMK is related to confidence in teaching technology (McRobbie et al. 2000) and that teachers' concept of technology is related to their pupils' concept of technology (De Vries 2000).

With respect to PCK (domain B) and its relations (c, e, and f), knowledge of pupils' conceptions (Davis et al. 2002; Jarvis and Rennie 1996b; Lewis 1999) and knowledge of the nature and purpose of technology (Jones and Moreland 2004) are found to positively affect teaching and learning. Although it is not evident which pedagogical approach is most favorable for teaching technology, it seems obvious that it is important to know which approaches and strategies are available and which are best to use in 
certain situations. It is empirically shown that PCK is associated with enhanced learning of pupils in primary technology education, and specifically with increased motivation and interest in technology (Jones and Moreland 2004). The relation between PCK and teachers' attitude is still unclear. Concerning teachers' attitude (domain C) and its relation with pupils' attitude (g), it is expected that teachers' attitude and confidence affects pupils' attitude towards technology, although empirical evidence is lacking. From the PATT studies in can be concluded that pupils' concept of technology is strongly related to their attitude towards technology (De Klerk Wolters 1989; De Vries 2000). This implies that it is important that teachers help their pupils developing a correct and comprehensive concept of technology.

The use of different instruments and diverse conceptualizations of the knowledge aspects in the reviewed studies made it complicated to compare the findings of these studies. In particular, PCK is a rather ambiguous concept, without a clear conceptualization. Besides, it is not claimed that the six aspects of teacher knowledge, represent the entire domain of technology-specific teacher knowledge. Several other aspects, and many subordinate aspects, could be added to the hypothetical diagram.

A critical comment on the method of reviewing might be that only literature in the field of technology education was searched, mainly because the focus was put on technologyspecific aspects of teacher knowledge. Literature on science education was occasionally included, because the knowledge domains of these two subject are partly overlapping. Nonetheless, studies from other subject areas may have useful results on teacher knowledge too, and might give some ideas for other knowledge aspects that are important regarding pupils' attitude towards technology.

In summary, teacher knowledge affects teaching, and, in turn, affects pupils' concept of and attitude towards technology. However, empirical evidence on the assumed relations between teacher knowledge and pupils' attitude is still poor. More research and, in particular, empirical evidence on teacher knowledge in technology education is clearly needed. It should be further explored how the aspects of teacher knowledge play a role in stimulating pupils' attitude towards technology. The hypothetical diagram presented in this review will serve as a helpful tool when investigating these relations empirically.

Open Access This article is distributed under the terms of the Creative Commons Attribution Noncommercial License which permits any noncommercial use, distribution, and reproduction in any medium, provided the original author(s) and source are credited.

\section{References}

Alamäki, A. (1999). How to educate students for a technological future: Technology education in early childhood and primary education. Dissertation, University of Turku, Turku.

Boekaerts, M., \& Boscolo, P. (2002). Interest in learning, learning to be interested. Learning and Instruction, 12, 375-382.

Boser, R., Palmer, J., \& Daugherty, M. (1998). Students attitudes toward technology in selected technology education programs. Journal of Technology Education, 10(1), 4-19.

Bransford, J., Brown, A., \& Cocking, R. (Eds.). (2004). How people learn: Brain, mind, experience and school. Washington DC: National Academy Press.

Cunningham, C., Lachapelle, C., \& Lindgren-Streicher, A. (2005). Assessing elementary school students' conceptions of engineering and technology. In Proceedings of the 2005 American Society for Engineering Education Annual Conference \& Exposition, American Society for Engineering Education, Portland.

Cunningham, C., Lachapelle, C., \& Lindgren-Streicher, A. (2006). Elementary teachers' understanding of engineering and technology. In Proceedings of the 2006 American Society for Engineering Education Annual Conference \& Exposition, American Society for Engineering Education, Chicago. 
Davies, T. (2000). Confidence! Its role in the creativity teaching and learning of design and technology. Journal of Technology Education, 12(1), 18-31.

Davis, E. (2004). Knowledge integration in science teaching: Analysing teachers' knowledge development. Research in Science Education, 34, 21-53.

Davis, R., Ginns, I., \& McRobbie, C. (2002). Elementary school students' understanding of technology concepts. Journal of Technology Education, 14(1), 35-50.

De Klerk Wolters, F. (1989). A PATT study among 10 to 12-year-olds. In F. De Klerk Wolters, I. Mottier, J. Raat, \& M. De Vries (Eds.), Teacher education for school technology. Eindhoven: Eindhoven University of Technology.

De Vries, M. (2000). Can we train researchers and teachers to make a team? Win-win strategies in technology education. In First Biennial International Conference on Technology Education Research Proceedings, Griffith University, Brisbane, pp. 1-12.

Fox-Turnbull, W. (2006). The influences of teacher knowledge and authentic formative assessment on student learning in technology education. International Journal of Technology and Design Education, 16, 53-77.

Garmire, E., \& Pearson, G. (Eds.). (2006). Tech Tally. Approaches to assessing technological literacy. Washington, DC: The National Academies Press.

Grossman, P. (1990). The making of a teacher: Teacher knowledge and teacher education. New York: Teachers College Press, Columbia University.

ITEA (2006). Technological literacy for all. A rationale and structure for the study of technology, 2nd edn. International Technology Education Association, Reston.

ITEA (2007). Standards for technological literacy. Content for the study of technology, 3rd edn. International Technology Education Association, Reston.

Jarvis, T., \& Rennie, L. (1996a). Perceptions about technology held by primary teachers in England. Research in Science and Technology Education, 14(1), 43-54.

Jarvis, T., \& Rennie, L. (1996b). Understanding technology: The development of a concept. International Journal of Science Education, 18(8), 977-992.

Johnston, J., \& Ahtee, M. (2006). Comparing primary student teachers' attitudes, subject knowledge and pedagogical content knowledge needs in a physics activity. Teaching and Teacher Education, 22(4), 503-512.

Jones, A., \& Compton, V. (1998). Towards a model for teacher development in technology education: From research to practice. International Journal of Technology and Design Education, 8, 51-65.

Jones, A., \& Moreland, J. (2004). Enhancing practicing primary school teachers' pedagogical content knowledge in technology. International Journal of Technology and Design Education, 14, 121-140.

Jones, A., Harlow, A., \& Cowie, B. (2004). New Zealand teachers' experiences in implementing the technology curriculum. International Journal of Technology and Design Education, 14, 101-119.

Lewis, T. (1999). Research in technology education: Some areas of need. Journal of Technology Education, $10(2), 41-56$.

Magnusson, S., Krajcik, J., \& Borko, H. (1999). Nature, sources, and development of pedagogical content knowledge for science teaching. In J. Gess-Newsome \& N. Lederman (Eds.), Examining pedagogical content knowledge, The construct and its implications for science education (Vol. 6., pp. 95-132). Dordrecht/Boston/London: Kluwer Academic Publishers.

McRobbie, C., Ginns, I., \& Stein, S. (2000). Preservice primary teachers' thinking about technology and technology education. International Journal of Technology and Design Education, 10, 81-101.

Moreland, J., \& Jones, A. (2000). Emerging assessment practices in an emergent curriculum: Implications for technology. International Journal of Technology and Design Education, 10, 283-305.

OECD (2006). Evolution of student interest in science and technology studies. Organisation for Economic Co-operation and Development, Global Science Forum, Paris.

Parkinson, E. (2001). Teacher knowledge and understanding of design and technology for children in the 311 age group: A study focusing on aspects of structures. Journal of Educational Psychology, 13, 4458.

Shulman, L. (1987). Knowledge and teaching: Foundations of the new reform. Harvard Educational Review, 57(1), 1-22.

Smith, D. (1999). Changing our teaching: The role of pedagogical content knowledge in elementary science. In J. Gess-Newsome \& N. Lederman (Eds.), Examining pedagogical content knowledge. The construct and its implications for science education, Science and Technology Education Library, Vol. 6. Dordrecht/Boston/London: Kluwer Academic Publishers.

Stables, K. (1997). Critical issues to consider when introducing technology education into the curriculum of young learners. Journal of Technology Education, 8(2) 
Stein, S., McRobbie, C., \& Ginns, I. (2002). Implications of missed opportunities for learning and assessment in design and technology education. Teaching and Teacher Education, 18, 35-49.

Twyford, J., \& Järvinen, E. M. (2000). The formation of children's technology concepts: A study of what it means to do technology from a child's perspective. Journal of Technology Education, 12(1), 32-48.

Van Driel, J., Verloop, N., \& De Vos, W. (1998). Developing science teachers' pedagogical content knowledge. Journal of Research in Science Teaching, 35(6), 673-695.

Verloop, N., Van Driel, J., \& Meijer, P. (2001). Teacher knowledge and the knowledge base of teaching. International Journal of Educational Research, 35, 441-461.

Volk, K., Yip, W., \& Lo, T. (2003). Hong Kong pupils' attitudes toward technology: The impact of design and technology programs. Journal of Technology Education, 15(1), 48-63.

Weber, K., \& Custer, R. (2005). Gender-based preferences toward technology education content, activities, and instructional methods. Journal of Technology Education, 16(2), 55-71.

Wilson, V., \& Harris, M. (2003). Designing the best: A review of effective teaching and learning of design and technology. International Journal of Technology and Design Education, 13, 223-241.

Wilson, V., \& Harris, M. (2004). Creating change? A review of the impact of design and technology in schools in England. Journal of Technology Education, 15(2), 46-65. 